\title{
CARINA oxygen data in the Atlantic Ocean
}

\author{
I. Stendardo ${ }^{1}$, N. Gruber ${ }^{1}$, and A. Körtzinger ${ }^{2}$ \\ ${ }^{1}$ Institute of Biogeochemistry and Pollutant Dynamics, ETH Zurich, Zürich, Switzerland \\ ${ }^{2}$ Leibniz Institute for Marine Sciences (IFM-GEOMAR), Chemical Oceanography, Kiel, Germany
}

Received: 7 July 2009 - Published in Earth Syst. Sci. Data Discuss.: 3 August 2009

Revised: 21 December 2009 - Accepted: 22 December 2009 - Published: 23 December 2009

\begin{abstract}
In the CARINA (Carbon dioxide in the Atlantic Ocean) project, a new dataset with many previously unpublished hydrographic data from the Atlantic, Arctic and Southern Ocean was assembled and subjected to careful quality control (QC) procedures. Here, we present the dissolved oxygen measurements in the Atlantic region of the dataset and describe in detail the secondary QC procedures that aim to ensure that the data are internally consistent. This is achieved by a cross-over analysis, i.e. the comparison of deep ocean data at places that were sampled by different cruises at different times. Initial adjustments to the individual cruises were then determined by an inverse procedure that computes a set of adjustments that requires the minimum amount of adjustment and at the same time reduces the offsets in an optimal manner. The initial adjustments were then reviewed by the CARINA members, and only those that passed the following two criteria were adopted: (i) the region is not subject to substantial temporal variability, and (ii) the adjustment must be based on at least three stations from each cruise. No adjustment was recommended for cruises that did not fit these criteria. The final CARINA-Oxygen dataset has 103414 oxygen samples from 9491 stations obtained during 98 cruises covering three decades. The sampling density of the oxygen data is particularly good in the North Atlantic north of about $40^{\circ} \mathrm{N}$ especially after 1987 . In contrast, the sample density in the South Atlantic is much lower. Some cruises appear to have poor data quality, and were subsequently omitted from the adjusted dataset. Of the data included in the adjusted dataset, $20 \%$ were adjusted with a mean adjustment of $2 \%$. Due to the achieved internal consistency, the resulting product is well suited to produce an improved climatology or to study longterm changes in the oxygen content of the ocean. However, the adjusted dataset is not necessarily better suited than the unadjusted data to address questions that require a high level of accuracy, such as the computation of the saturation state.
\end{abstract}

\section{Data coverage and parameters measured}

Repository-Reference: doi:10.3334/CDIAC/otg.CARINA.ATL.V1.0 http://cdiac.ornl.gov/ftp/oceans/CARINA/CARINA_

Database/CARINA.ATL.V1.0/

Available at: http://cdiac.ornl.gov/oceans/CARINA/Carina_inv.html

Coverage: $60^{\circ} \mathrm{S}-75^{\circ} \mathrm{N} ; 80^{\circ} \mathrm{W}-34^{\circ} \mathrm{E}$

Location Name: Atlantic Ocean

Date/Time Start: 1977-10-07

Date/Time End: 2006-02-02

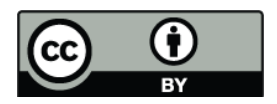

Correspondence to: I. Stendardo

(ilaria.stendardo@env.ethz.ch)

Published by Copernicus Publications. 


\begin{tabular}{lllll}
\hline $\begin{array}{l}\text { Data Product } \\
\text { Parameter Name }\end{array}$ & $\begin{array}{l}\text { Data Product } \\
\text { Flag Name }\end{array}$ & $\begin{array}{l}\text { Exchange File } \\
\text { Parameter Name }\end{array}$ & $\begin{array}{l}\text { Exchange File } \\
\text { Flag Name }\end{array}$ & Units \\
\hline starion & & STANBR & & \\
day & DATE & & \\
month & & DATE & & \\
year & DATE & & \\
latitude & & LATITUDE & & Decimal degree \\
longitude & & LONGITUDE & & Decimal degree \\
cruiseno & & & & \\
$\begin{array}{l}\text { depth } \\
\text { temperature }\end{array}$ & & CTDTMP & & Meter \\
salinity & sf & SALNTY & SALINITY_FLAG_W & \\
oxygen & of & OXYGEN & OXYGEN_FLAG_W & $\mu$ mol $\mathrm{kg}^{-1}$ \\
\hline
\end{tabular}

For a complete list of parameters see Key et al. (2009).

\section{Introduction}

CARINA (Carbon dioxide in the Atlantic Ocean) is a data synthesis project with the aim to assemble a large collection of ocean interior data from hydrographic cruises in the Arctic, Atlantic and Southern Ocean, many of which were previously unavailable to the public (Tanhua et al., 2009a). Because the CARINA dataset consists of data collected by many different laboratories over several decades and often using different methods, these data need to be carefully quality controlled in order to obtain datasets that are useful for describing the large-scale distribution of properties. In addition, if the goal is to study long-term trends, it is crucial to obtain an internally consistent dataset, which can only be achieved by applying secondary quality control (QC) procedures to the data (Key et al., 2004; Lamb et al., 2002; Johnson et al., 2001).

While the primary QC consists in the identification of the outliers and errors in the data, the secondary QC consists of the quantification and reduction of the analytical errors in the reported values without the elimination of real temporal changes (Johnson et al., 2001). The goal is to ensure internal consistency. Given the lack of traceable standards for many oceanographic variables, including oxygen and nutrients, the secondary QC may not result in more accurate values, however. For the purpose of the analysis of longterm changes, internal consistency is sufficient. However, if the goal is to compute the magnitude and variability of the air-sea gas exchange of oxygen, then high accuracy is required and this product may not provide it. The quality of the data and the offsets are assessed using a crossover analysis whereby property differences between individual cruises on deep-ocean isopycnals are quantified. Such a crossover analysis is based on the assumption that the investigated properties, e.g. oxygen, salinity and nutrients, in the deep waters have not changed in between the individual cruises (Lamb et al., 2002), so that the identified difference is usually attributed to an analytical error. On the basis of the identified offsets, a set of adjustments is inferred that is then applied to the original data in order to obtain an adjusted, internally consistent data set (see e.g. the GLobal Ocean Data Analysis Project (GLODAP) (Key et al., 2004)).

As part of the CARINA project in the Atlantic Ocean, the primary and secondary QC has been undertaken for the following parameters: salinity (Tanhua et al., 2009a), total inorganic carbon $\left(\mathrm{TCO}_{2}\right)$ (Pierrot et al., 2009), total alkalinity (TA) (Velo et al., 2009), nitrate, phosphate, silicic acid (Tanhua et al., 2009c), oxygen (this study), CFC-11, CFC12, CFC-13 and $\mathrm{CCl}_{4}$ (Steinfeldt et al., 2009). Details can be found in Key et al. (2009) and Tanhua et al. (2009b) in this issue, as they describe the methods developed for the primary and secondary QC and the assemblage of the dataset.

The aim of this paper is to describe the oxygen data in the CARINA dataset, to document the quality control procedures applied to the oxygen data, and to justify all the adjustments.

\section{Data}

CARINA consists of a collection of 188 hydrographic cruises or projects, divided into three regions, the Atlantic (CARINA-ATL), the Arctic Mediterranean Seas (CARINAAMS) and the Southern Ocean (CARINA-SO) regions. This paper focuses on the oxygen data from the Atlantic Ocean, which is the region with the highest number of cruises (98 cruises). The CARINA-ATL region has five cruises in common with the CARINA-AMS group and five cruises in common with the CARINA-SO group, in order to ensure consistency across the three regions.

For the secondary quality control, six hydrographic cruises from the World Ocean Circulation Experiment (WOCE) as synthesized by GLODAP (Key et al., 2004) were added to ensure consistency with this prior synthesis effort. The GLODAP project performed a rigorous secondary quality control on the carbon data, however regarding the oxygen adjustments, GLODAP group applied the biases determined by Gouretski and Jancke (2001) in their analysis of the WOCE and historical hydrographic data. The data from these reference cruises are not included in the final product. 


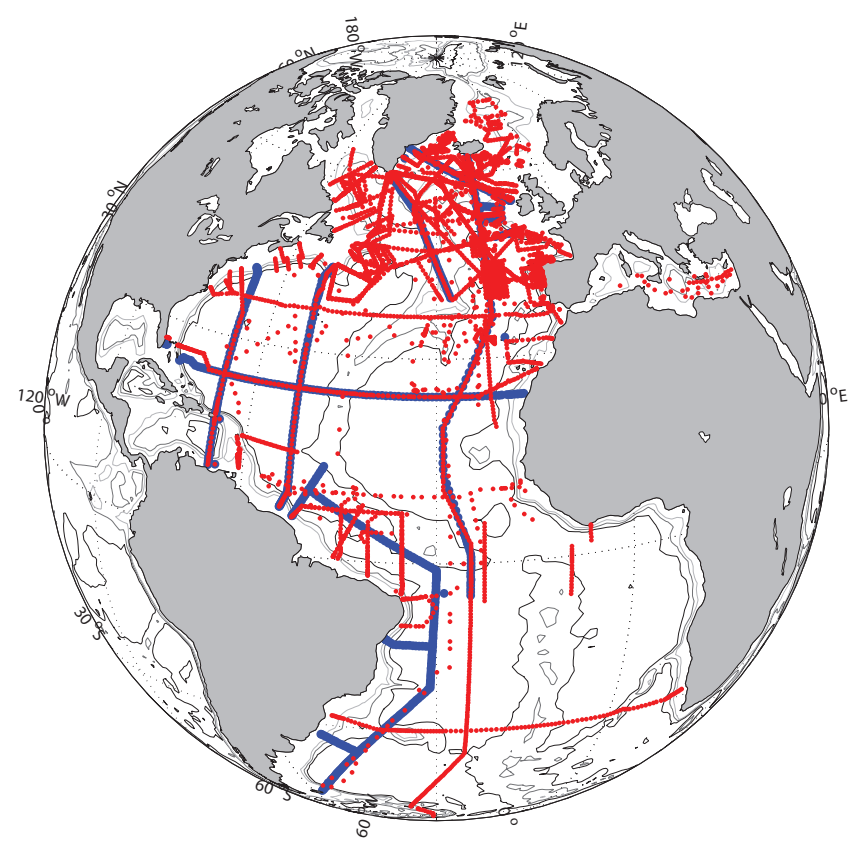

Figure 1. Map of the CARINA dataset of the Atlantic region (CARINA-ATL), with the station positions of cruises with oxygen data. In red are the stations from the final CARINA-ATL dataset, in blue are the stations of the reference cruises.

Twenty-nine cruises from the CARINA-ATL dataset were identified as core cruises, primarily on the basis of their having a good spatial distribution and a higher expected data quality. During the computation of the adjustments, more weight was given to these core cruises as well as to the six WOCE cruises, ensuring that cruises with lower data quality are not causing unwarranted adjustments in the cruises with higher data quality.

\subsection{Oxygen data}

The CARINA-ATL dataset contains 103414 oxygen samples from 9491 stations. A map of the locations of the hydrographic stations with at least one oxygen sample (Fig. 1) shows that CARINA-ATL has a good spatial distribution, with the densest coverage in the northeast Atlantic. The data span three decades, with the earliest samples stemming from 1977 and the latest samples taken in 2006 (Fig. 2). The majority of the data stem from the 1990s, with a reasonably good coverage between 1990 and 2005. The years 1997, 1998, 2001 and 2003 have the greatest number of samples, largely driven by the fact that these years include basinwide transects (Fig. 3). Maps of the data from 1977 to 2007 with a time step of five years show that from 1992 to 2007 the spatial coverage is good, and particularly in the last five years is dominated by long transects (Fig. 3). From 1987 to 1991 the data are especially concentrated in the northeastern part, while from 1977 to 1986 there are only few

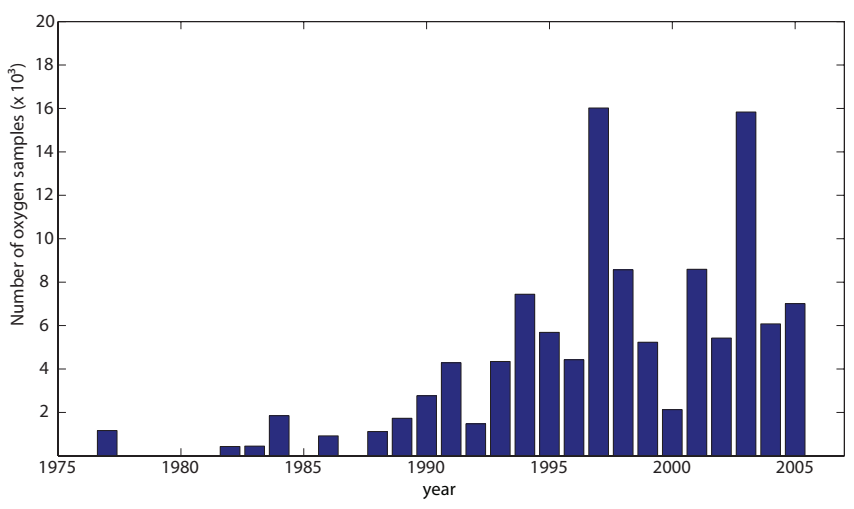

Figure 2. Number of samples for oxygen by year in CARINA-ATL.

data stemming from along the Iberian coast. The only cruise in 1977 (29CS19771007 cruise \# 51) is one of the Galicia cruises (Galicia4) and has 88 stations with oxygen data only in the upper $1500 \mathrm{~m}$. For this reason, we did not include this cruise in the secondary QC, i.e. no adjustment is recommended (Table 1). For similar reasons, eight other cruises were not considered in the second QC and labeled as NC (Not Considered) in Table 1.

In order to provide an overview of the oxygen distribution, we plot in Fig. 4 the oxygen data versus depth for 11 large-scale regions, separating the time periods by color. This plot reveals, for example, that all oxygen data before 1986 are from the upper $2000 \mathrm{~m}$ only (green dots in panel d). The vertical distribution of oxygen in the Atlantic Ocean reflects the combined effects of gas exchange, the photosynthesis/remineralization cycle, and ocean circulation. Near the surface ocean, rapid gas exchange keeps oxygen very near the saturation concentration (Sarmiento and Gruber, 2006), despite oxygen production from photosynthesis and oxygen demand by the upwelling/mixing of low oxygen waters from below. In the interior, the oxygen demand from the remineralization of the sinking organic matter leads to decreasing oxygen concentrations, but this decrease is modified strongly by the level by which ocean circulation and mixing are able to transport oxygen from the upper ocean into the deep. For example, oxygen rich water penetrates into the deep North Atlantic as a result of the southward spreading of recently ventilated North Atlantic Deep Water. This easily identifiable water mass that occupies the depths between $1000 \mathrm{~m}$ to $4000 \mathrm{~m}$ and extends southward from the Labrador Sea to the Antarctic Divergence (Fig. 4, panel c, e, and g). The Labrador Sea Water (LSW) is also distinguishable in the Labrador Sea as a huge volume of nearly homogeneous water with high oxygen content. This water mass is a product of winter deep convection (Fig. 4 northwest region, panel a). In the intermediate-depth eastern tropical ocean (Fig. 4 the eastern region in the tropical zones, panel $\mathrm{f}$ ) it is also possible to identify the horizontal oxygen minimum zone (OMZ). 

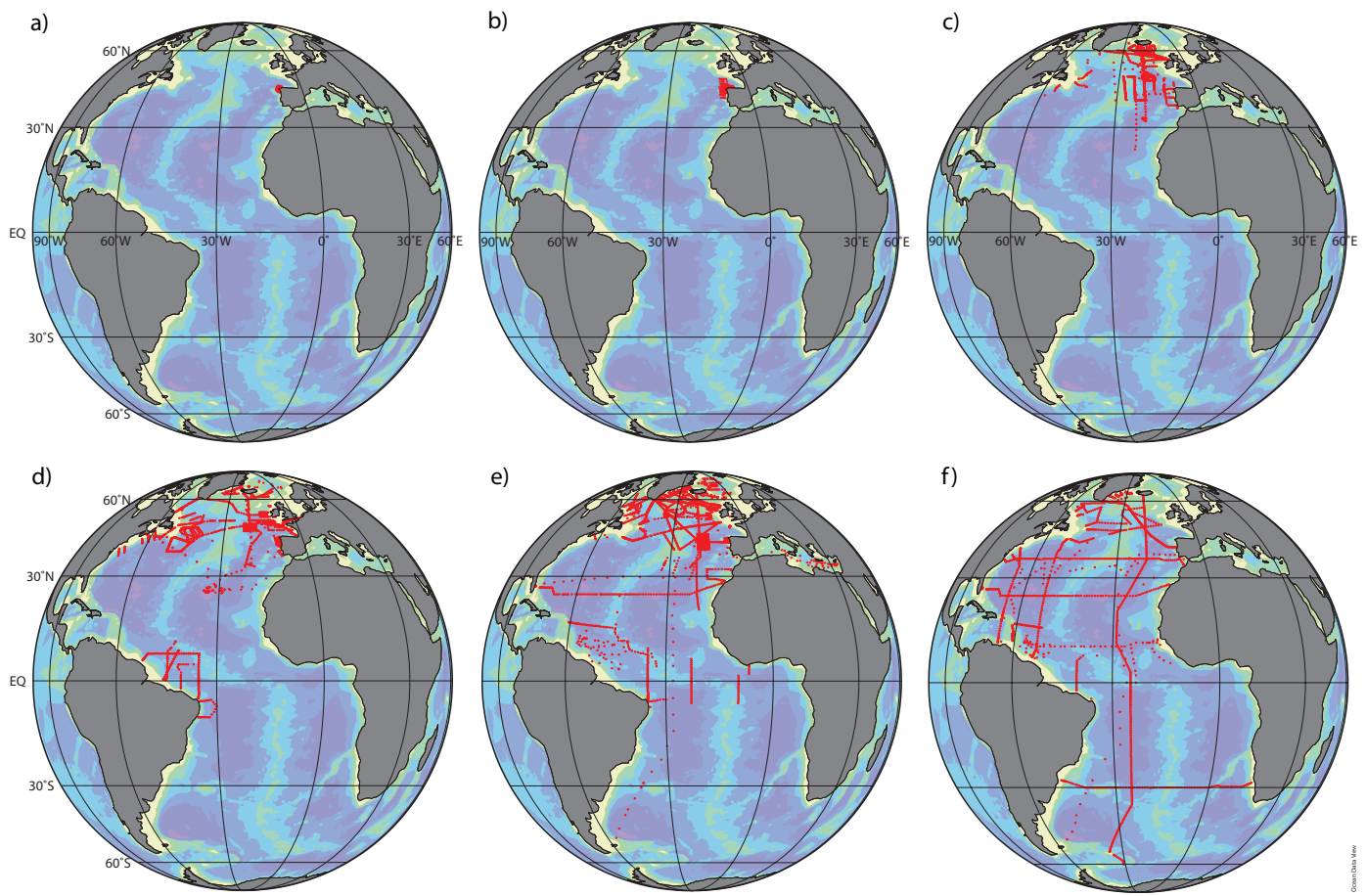

Figure 3. Maps showing the temporal distribution (5 year intervals) of stations that have oxygen samples in the final product of CARINAATL (without the 6 reference cruises from GLODAP, see Sect. 2): (a) 1977 to 1981; (b) 1982 to 1986; (c) 1987 to 1991; (d) 1992 to 1996; (e) 1997 to 2001, and (f) 2002 to 2007.

\section{Methods}

All CARINA data were first subjected to a primary QC, i.e. the detection and flagging of outliers and other irregular data points (Tanhua et al., 2009b). Our subgroup was responsible for the secondary QC of the oxygen data. The method used for the secondary QC is described in detail by Tanhua et al. (2009b). We briefly summarize here this method with emphasis on the issues specific to oxygen.

The first step of the secondary QC consists of a crossover analysis (e.g. Johnson et al., 2001), where the difference is computed between two cruises (defined as an offset) that are crossing each other or, as is often the case in the Atlantic, are along repeated tracks. For the computations of the offsets, only data deeper than $1500 \mathrm{dbar}$ (about $1500 \mathrm{~m}$ ) were used in order to eliminate from the analysis the upper water column that is more variable in time. The quality control procedures/criteria differed for two cruises, cruise \# 93 and \# 107. These cruises were added in the later stage of the project, and because they have only few samples deeper than $1500 \mathrm{~m}$, the minimum depth for the crossovers was set manually at $1000 \mathrm{~m}$. For each crossover, stations were selected from an area that was within a radius of 2 degrees of latitude (i.e. about $222 \mathrm{~km}$ ). In order to better compare samples in the deep ocean, the analysis was performed on $\sigma_{4}$ density surfaces. For each oxygen sample, its corresponding density was first computed, and then the data from each profile were interpolated with a Piecewise Cubic Hermite interpolating scheme to a number of standard densities. Those were selected in such a way that the interpolated values were equally distributed in depth space (Tanhua et al., 2009b). The oxygen offsets and their standard deviations were computed as multiplicative factors. We opted for a multiplicative instead of an additive approach for two primary reasons: First, this avoids the potential problem of obtaining negative values in low oxygen regions. Second, this reflects the fact that the preparation of the standard is the most likely source of error for the measurement, and this source of error is of multiplicative nature (see also Tanhua et al., 2009b). We suspect that choosing an additive approach would not have resulted in a drastically different adjusted dataset since the range of oxygen values in the North Atlantic is relatively limited, so that there is little expected difference between a multiplicative and additive approach.

To perform the crossover analysis we used the running cluster routine developed by Tanhua et al. (2009a). In this routine, the offset is computed by first comparing each station from the first cruise to each station from the second cruise in the crossing area, and then by computing the weighted mean and standard deviation of the differences. Relative to other crossover analysis methods, this running cluster method minimizes the potential for comparing stations that sample different hydrographic settings and also minimizes the need for a manual definition of subregions. 
Table 1. Table of adjustments estimated from WDLSQ method. The column \# indicates the cruise number in the final product. The columns "Core" and "Ref" identify the core and references cruises (marked as $\mathrm{x}$ ). The inversion method adjustment column refers to the results from the WDLSQ inversion with the corresponding mean and standard deviation in the subcolums. The recommendation column represents the adjustment proposed on the base of the crossover analysis and inversions, the cruises in common with the two other groups are labeled as ATL+AMS and ATL+SO. The reference cruises are included in the table and marked with stars in the \# column although they will not be included in the final CARINA product. The cruises where it was not possible to compute the adjustment are labeled as NC (not considered), the cruises where it was not possible to suggest an adjustment because of few or no data are labeled as ND. The cruises that belong the CARINA-AMS group are label as AMS. The last two columns are the references for the oxygen samples and the chief scientists of the cruises.

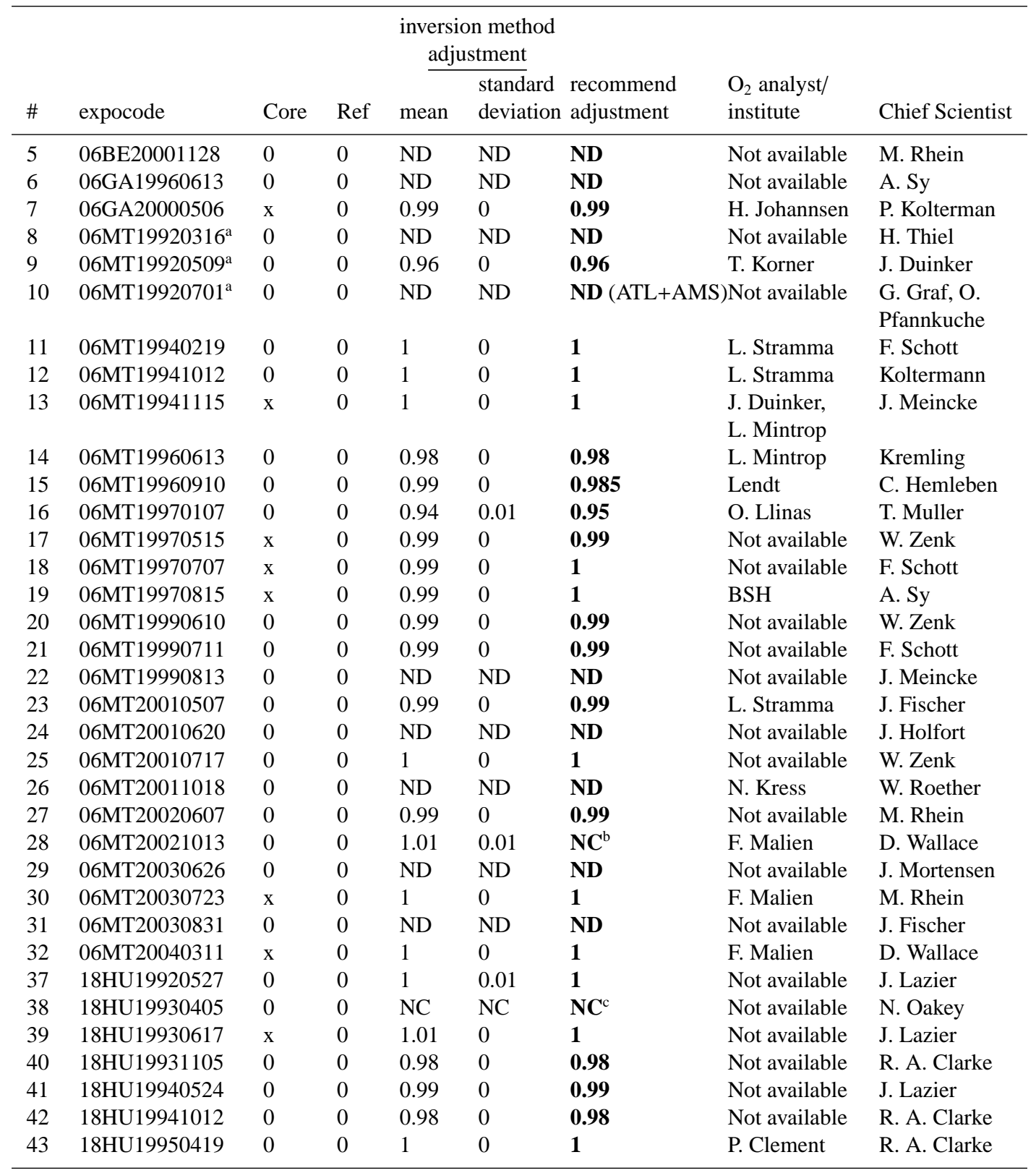

\footnotetext{
a The original cruise 06MT19920322 was several legs, so we split the cruise into three: 06MT19920316, 06MT19920509 and 06MT19920701.

$\mathrm{b}$ NC because only one crossover for this cruise.

${ }^{c}$ No deep data so not included in the 2nd level QC.

${ }^{\mathrm{d}}$ Recommended by the AMS group.

${ }^{\mathrm{e}}$ Added in the later stage of the project, because few samples deeper than $1500 \mathrm{~m}$, the minimum depth for the crossovers was set manually at $1000 \mathrm{~m}$

${ }^{\mathrm{f}}$ No deep data for the stations in the North Atlantic. Recommended by the AMS group.

$\mathrm{g}$ The first number refers to the adjustment recommended only from stations 1 to 43 , the second number refers to no adjustment from station 44 to last.
} 
Table 1. Continued.

\begin{tabular}{|c|c|c|c|c|c|c|c|c|}
\hline \# & expocode & Core & Ref & $\begin{array}{l}\text { invers } \\
\text { adj }\end{array}$ & $\begin{array}{l}\text { n method } \\
\text { stment } \\
\begin{array}{l}\text { standard } \\
\text { deviation }\end{array}\end{array}$ & $\begin{array}{l}\text { recommend } \\
\text { adjustment }\end{array}$ & $\begin{array}{l}\mathrm{O}_{2} \text { analyst/ } \\
\text { institute }\end{array}$ & Chief Scientist \\
\hline 44 & 18HU19970509 & $\mathrm{x}$ & 0 & 1 & 0 & 1 & P. Strain/J. Lazier & R. A. Clarke \\
\hline 51 & 29CS19771007 & 0 & 0 & $\mathrm{NC}$ & $\mathrm{NC}$ & $\mathbf{N C}^{\mathrm{c}}$ & Not available & F. Fraga \\
\hline 52 & 29CS19930510 & 0 & 0 & 0.99 & 0 & 1 & $\begin{array}{l}\text { A. Alvarez/ } \\
\text { G. Roson }\end{array}$ & J. M. Cabanas \\
\hline 53 & 29GD19821110 & 0 & 0 & 1.04 & 0.01 & 1.04 & Not available & F. Fraga \\
\hline 54 & 29GD19831201 & 0 & 0 & $\mathrm{NC}$ & $\mathrm{NC}$ & $\mathbf{N C}^{\mathrm{c}}$ & Not available & F. Fraga \\
\hline 55 & 29GD19840218 & 0 & 0 & 0.99 & 0.01 & 1 & Not available & F. Fraga \\
\hline 56 & 29GD19840711 & 0 & 0 & 0.99 & 0 & 0.98 & Not available & F. Fraga \\
\hline 57 & 29GD19860904 & 0 & 0 & 1 & 0 & 1 & Not available & F. Fraga \\
\hline 60 & 29HE19980730 & 0 & 0 & 1.01 & 0.01 & 1 & E.D. de Armas & F.F. Perez \\
\hline 61 & 29HE20010305 & 0 & 0 & 0.99 & 0.01 & 0.99 (ATL+SO) & E.D. de Armas & A. Rios \\
\hline 62 & 29HE20020304 & $\mathrm{x}$ & 0 & 1 & 0.01 & $1(\mathrm{ATL}+\mathrm{SO})$ & C. Castro & F.F. Perez \\
\hline 63 & 29HE20030408 & 0 & 0 & 0.99 & 0 & 1 & C. Castro & A. Rios \\
\hline 64 & 31AN19890420 & 0 & 0 & 1 & 0 & 1 & Not available & P. Brewer?? \\
\hline 65 & 316N19971005 & 0 & 0 & 1.01 & 0 & 1 & G. Knapp & R. Curry \\
\hline 66 & 316 N20010627 & 0 & 0 & ND & ND & ND & Not available & $\begin{array}{l}\text { D. Capone, E. } \\
\text { Carpenter }\end{array}$ \\
\hline 68 & 316 N20030922 & $\mathrm{x}$ & 0 & 1.01 & 0 & 1 & ODF & $\begin{array}{l}\text { J. Toole, A. } \\
\text { MacDonald }\end{array}$ \\
\hline 69 & $316 \mathrm{~N} 20031023$ & $\mathrm{x}$ & 0 & 1.01 & 0 & 1 & ODF & $\begin{array}{l}\text { T. Joyce, } \\
\text { W. Smethie }\end{array}$ \\
\hline 71 & 32EV19910328 & 0 & 0 & 1 & 0 & 1 & Not available & R. Pickart \\
\hline 81 & $32 \mathrm{OC} 19950529$ & 0 & 0 & 1.01 & 0 & 1 & Not available & R. Pickart \\
\hline 84 & 33LK19960415 & 0 & 0 & 1.01 & 0.01 & 1 & C. Oudot & Y. Gouriou \\
\hline 85 & 33RO19980123 & $\mathrm{x}$ & 0 & 0.98 & 0 & 0.99 & C. Mordy & $\begin{array}{l}\text { D. Bitterman, } \\
\text { K. Lee }\end{array}$ \\
\hline 86 & 33RO20030604 & $\mathrm{x}$ & 0 & 1 & 0 & 1 & $\begin{array}{l}\text { C. Mordy, } \\
\text { G. Johnson }\end{array}$ & $\begin{array}{l}\text { J. Bullister, } \\
\text { N. Gruber }\end{array}$ \\
\hline 87 & 33RO20050111 & $\mathrm{x}$ & 0 & 1.01 & 0 & $1(\mathrm{ATL}+\mathrm{SO})$ & $\begin{array}{l}\text { AOML/ } \\
\text { U.Miami }\end{array}$ & $\begin{array}{l}\text { R. Wanninkhof, } \\
\text { S. Doney }\end{array}$ \\
\hline 89 & 33SW20010102 & 0 & 0 & $\mathrm{NC}$ & $\mathrm{NC}$ & $\mathbf{N C}^{\mathrm{c}}$ & Not available & $\begin{array}{l}\text { A. Michaels/ } \\
\text { D. Capone }\end{array}$ \\
\hline 90 & 33SW20030418 & 0 & 0 & ND & ND & ND & Not available & $\begin{array}{l}\text { D. Capone/ } \\
\text { A. Subramaniam }\end{array}$ \\
\hline 91 & 34AR19970805 & 0 & 0 & 1 & 0 & $\mathbf{N C}^{\mathrm{d}}(\mathrm{ATL}+\mathrm{AMS}$ & )T. Tanhua & $\begin{array}{l}\text { H. Gronvall/ } \\
\text { J. Launiainen }\end{array}$ \\
\hline 92 & 35A320010203 & 0 & 0 & 1 & 0.01 & 1 & Not available & L. Prieur \\
\hline 93 & $35 \mathrm{~A} 320010322^{\mathrm{e}}$ & 0 & 0 & 1.01 & 0 & 1 & Not available & M. Bianchi \\
\hline 94 & 35LU19890509 & 0 & 0 & 0.99 & 0 & 1 & F. Fraga & Not available \\
\hline 95 & 35LU19950909 & 0 & 0 & 1 & 0.01 & 1 & $\begin{array}{l}\text { P. Fournier, } \\
\text { C. Oudot }\end{array}$ & Y. Gouriou \\
\hline 106 & 35TH19990712 & 0 & 0 & 1 & 0 & 1 & Y. Gouriou & Y. Gouriou \\
\hline 107 & $35 \mathrm{TH} 20010823^{\mathrm{e}}$ & 0 & 0 & 1.01 & 0.01 & 1 & Not available & J.C. Gascard \\
\hline 108 & 35TH20020611 & $\mathrm{x}$ & 0 & 1 & 0 & 1 & P. Morin & H. Mercier \\
\hline 109 & 35ТH20040604 & $\mathrm{x}$ & 0 & 1.01 & 0 & 1 & P. Morin & T. Huck \\
\hline
\end{tabular}


Table 1. Continued.

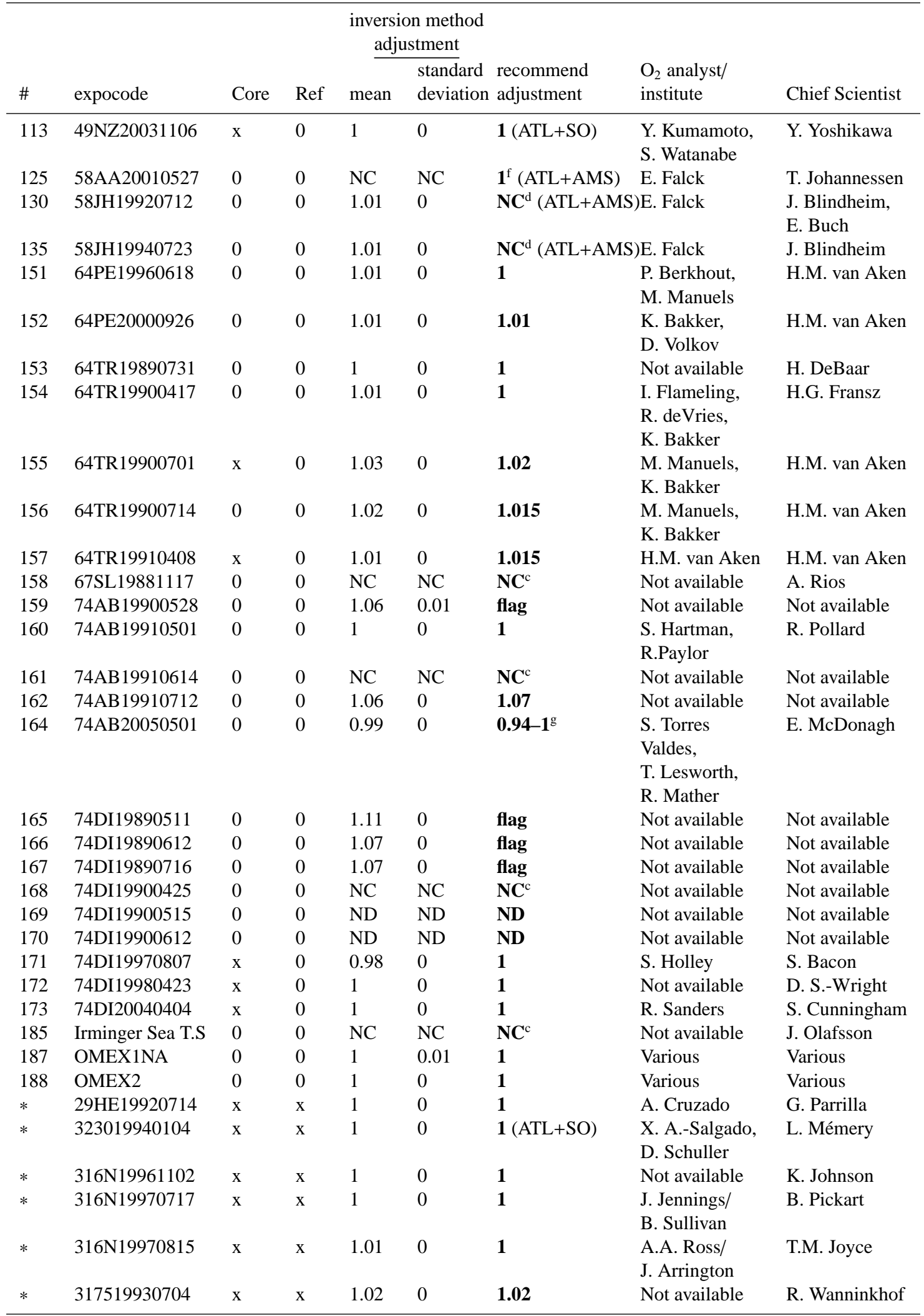



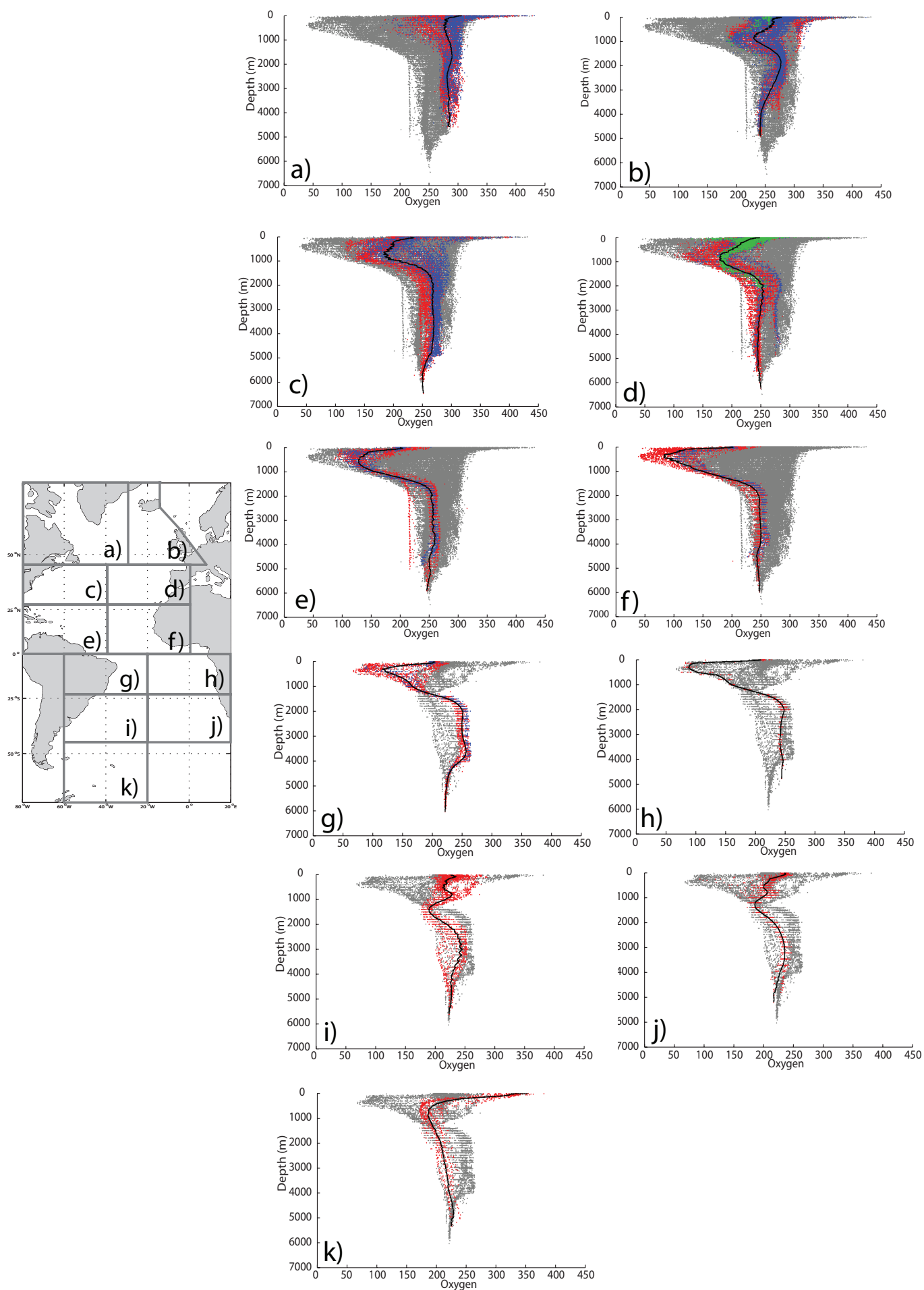

Figure 4. Overview of the oxygen distribution in the dataset depicted as vertical profiles for 11 separate regions: (a) $70^{\circ} \mathrm{N}-46^{\circ} \mathrm{N}$ and $80^{\circ} \mathrm{W}-30^{\circ} \mathrm{W}$, (b) $70^{\circ} \mathrm{N}-46^{\circ} \mathrm{N}$ and $30^{\circ} \mathrm{W}-20^{\circ} \mathrm{E}$ except the cruises in the Arctic Ocean north of $60^{\circ} \mathrm{N},(\mathbf{c}) 46^{\circ} \mathrm{N}-23^{\circ} \mathrm{N}$ and $80^{\circ} \mathrm{W}-40^{\circ} \mathrm{W}$, (d) $46^{\circ} \mathrm{N}-23^{\circ} \mathrm{N}$ and $40^{\circ} \mathrm{W}-0^{\circ}$ (e) $23^{\circ} \mathrm{N}-\mathrm{EQ}$ and $80^{\circ} \mathrm{W}-40^{\circ} \mathrm{W}$, (f) $23^{\circ} \mathrm{N}-\mathrm{EQ}$ and $40^{\circ} \mathrm{W}-0^{\circ}$ (g) Eq-23 $\mathrm{S}$ and $60^{\circ} \mathrm{W}-20^{\circ} \mathrm{W}$, (h) Eq-23 $\mathrm{S}$ and $20^{\circ} \mathrm{W}-20^{\circ} \mathrm{E}$ (i) $23^{\circ} \mathrm{S}-46^{\circ} \mathrm{S}$ and $60^{\circ} \mathrm{W}-20^{\circ} \mathrm{W}$, (j) $23^{\circ} \mathrm{S}-46^{\circ} \mathrm{S}$ and $20^{\circ} \mathrm{W}-20^{\circ} \mathrm{E}$, (k) $46^{\circ} \mathrm{S}-70^{\circ} \mathrm{S}$ and $60^{\circ} \mathrm{W}-20^{\circ} \mathrm{W}$. Shown in gray is the vertical distribution for the entire North Atlantic (a, b, c, d, e and f) and the entire South Atlantic (g, h, i, j and k) respectively. Shown in red is the vertical distribution in the area where the panel is located on the map from 1997 to 2007, in blue is the vertical distribution from 1987 to 1996 and in green is the vertical distribution from 1977 to 1986 . The black line is the mean profile of the entire data in that area interpolated with a piecewise Cubic Hermite Interpolating scheme. Oxygen units are in $\mu \mathrm{mol} \mathrm{kg}{ }^{-1}$ 
The second step of the secondary QC consists of the computation of an optimal set of adjustments that are then applied to the data in order to generate an internally consistent data set. This is achieved by writing the problem as a system of linear equations that relate the data in each cruise to those in all crossing cruises and then inverting this matrix to find a set of adjustments that minimizes the offsets among all the cruises (Johnson et al., 2001). Three variants of a least square method were used: the (unweighted) Simple Least Squares (SLSQ) method, the Weighted Least Square (WLSQ) method, and the Weighted Damped Least Square (WDLSQ) method (Johnson et al., 2001; Tanhua et al., 2009a). For the WLSQ schemes, the inverse of the standard deviation of the offsets were used as weights. In addition, for the WDLSQ schemes, the reference and core cruises were weighted higher than the other cruises in order to ensure a lower level of adjustments in these cruises compared to the others. Finally, the weights included also a temporal term, in order to give less weight to offsets that are between cruises that sampled a region many years apart. This is achieved by multiplying the standard deviation of the crossovers with a time factor $\mathrm{K}_{T}$ computed as follows:

$K_{T}=1+0.1 \Delta$ year

where, $\Delta y e a r$ represents the time in years between the two cruises.

We use the results from the WDLSQ variant for further processing, but we show that the other variants give similar results. As the offsets for oxygen were computed as multiplicative factors, the adjustments were of a multiplicative nature as well.

The third step of the secondary QC consists of the careful cruise-by-cruise inspection and evaluation of the suggested adjustments. This step was undertaken manually by the CARINA analysts. It was decided that only cruises for which adjustments larger than $1 \%$ difference from 1 , i.e. smaller than 0.99 or larger than 1.01 were considered. If in doubt, for example, if there were indications that an apparent offset was driven by true variability, no adjustment is proposed. A detailed discussion for those cruises that required special attention is provided below. The cruises with an adjustment of less than $1 \%$ from 1 are not adjusted, i.e. an adjustment factor of 1 is proposed instead.

As a last step, the overall level of internal consistency of the CARINA-ATL oxygen data was computed using the weighted mean (WM) of the absolute values of the offset $(D)$ of $L$ crossovers with their uncertainty $(\sigma)$. (Note that Tanhua et al. (2009c) refers to this quantity as the overall accuracy of the dataset).

$\mathrm{WM}=\frac{\sum_{i=1}^{L} D(i) / \sigma(i)^{2}}{\sum_{i=1}^{L} 1 / \sigma(i)^{2}}$

This analysis gives a level of internal consistency of $0.8 \%$ (Fig. 5). For a typical ocean interior oxygen concentration of

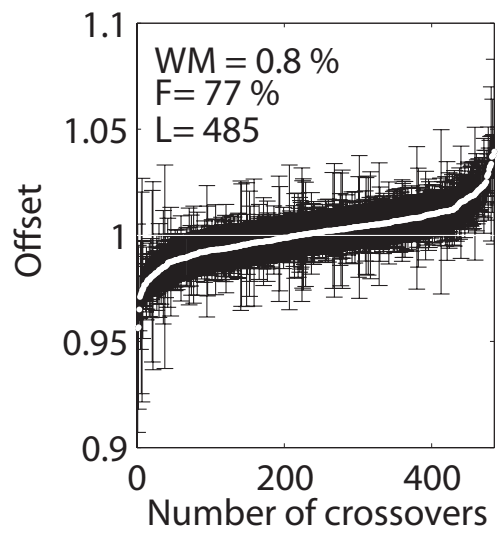

Figure 5. Plot of the offsets calculated for each crossover in the final product of CARINA-ATL after adjustments have been applied. WL: the weighted mean of the offsets; F: the percentage of offsets indistinguishable from 1 within their uncertainty; L: the number of crossovers.

$250 \mu \mathrm{mol} \mathrm{kg}{ }^{-1}$, this translates into a level of consistency of $2 \mu \mathrm{mol} \mathrm{kg}{ }^{-1}$, i.e. the estimated level of consistency is about a factor of two larger than the typical precision of dissolved oxygen measurements.

\section{Results}

The offset analysis computed by the automated cluster routine reveals a large range of multiplicative offsets for oxygen, from more than 0.9 to less than 1.1 (Fig. 6a). However, given the substantial uncertainty in the offsets, $43 \%$ of the crossovers are statistically indistinguishable from 1 . The smallest offset of 0.89 with a standard deviation of 0.01 exists between the Discovery cruise 74DI19890511 (cruise \# 165) and the Meteor cruise 06MT19960910 (cruise \# 15). This offset is driven mainly by the first cruise for which an upward adjustment of 1.11 will be proposed (see subsection 4.1.3). Regarding the second cruise (see Table 1), we also propose an adjustment of 0.985 . The biggest offset of 1.11 with a standard deviation of 0.01 corresponds to the offset between the C. Darwin cruise 74AB19910501 (cruise \# 160) and the Discovery cruise in 1989 (74DI19890511). The offset is driven by the Discovery cruise, while the C. Darwin cruise (see Table 1) does not need an adjustment.

After the first round of the inversion, the remaining offsets are much smaller, largely independent of which inversion method is used (Fig. 6b-d). In the case of the SLSQ the offset reduction leads to $77 \%$ of all cruise offsets being indistinguishable from 1, while for WLSQ and WDLSQ, this percentage is $73 \%$. The suggested offsets for each cruise computed by the WDLSQ method (shown in black in Fig. 7) generally cluster in between our threshold barriers (0.99 to 1.01), but there are a significant number 

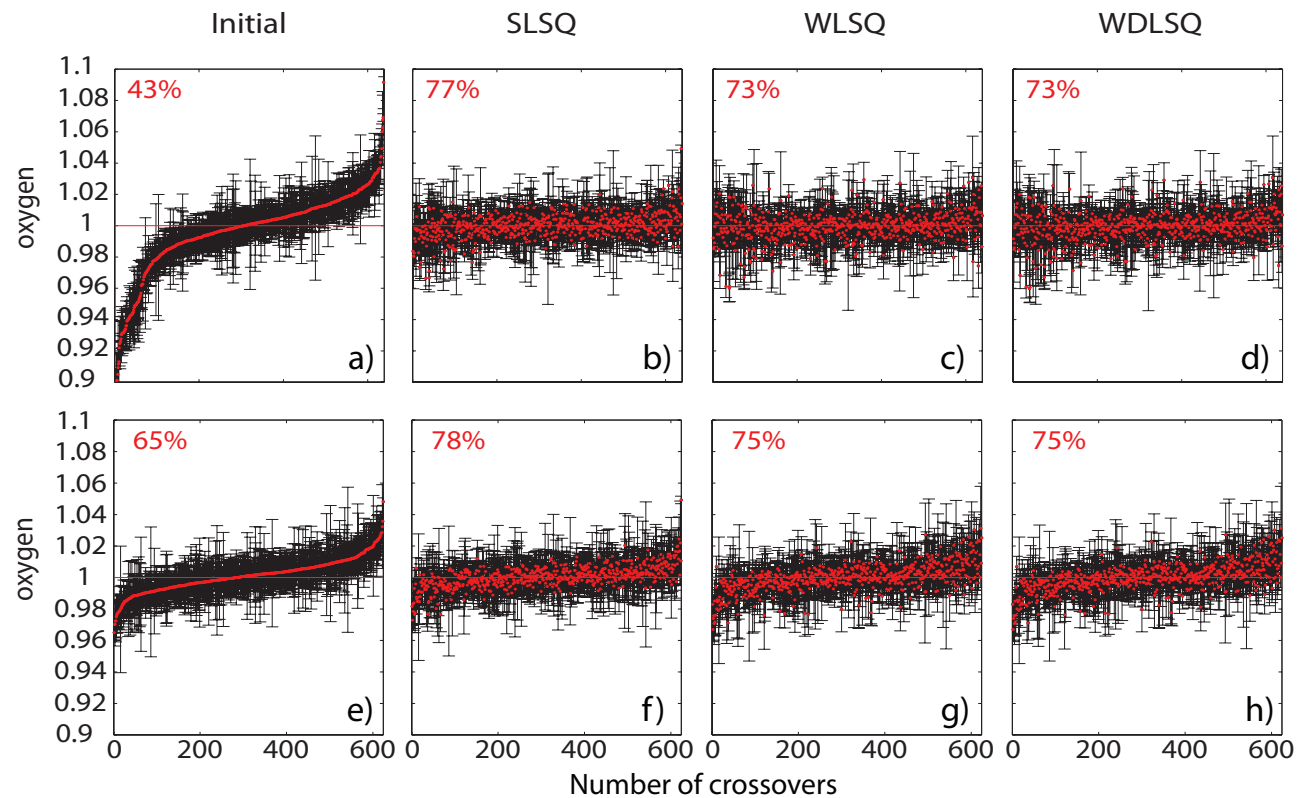

Figure 6. Plot of the offsets for each crossover (red dots) and their uncertainties (black error bars). The offsets from the reference cruises are also included in the figure. The first row, i.e. (a-d) corresponds to the results before any suggested adjustment have been applied, while the second row, i.e. (e-h) corresponds to the results after the manually edited adjustments were applied. First column, i.e. (a) and (e), show the results from the offset analysis ordered by offset. The second, third, and forth columns depict the offsets after the inversions. (b) and (f) are results from the Simple least Square method (SLSQ), (c) and (g) are results from Weighted Least Square method (WLSQ), and (d) and (h) are results from the Weighted Damped Least Square method (WDLSQ). The red numbers in the upper-left corner of each panel are the percentage of crossovers that are statistically indistinguishable from zero.

of cruises that require much larger adjustments. Particularly noteworthy are the following cruises: 74DI19890511 (cruise \# 165) with the biggest upward adjustment of 1.11; cruises 74DI19890612 (cruise \# 166) and 74DI19890716 (cruise \# 167) that require adjustments of 1.07 , cruises 74AB19910712 (cruise \# 162) and 74AB19900528 (cruise \# 159) needing adjustments of 1.06, cruise 29GD19821110 (cruise \# 53) that needs an upward adjustment of 1.04, and finally cruise 64TR19900701 (cruise \# 155) that needs an adjustment of 1.02 and cruises 64TR19900714 (cruise \# 156), and 64TR19910408 (cruise \# 157) for which an adjustment of 1.015 is proposed. Regarding the downward adjustments, noteworthy are the cruises 06MT19970107 (cruise \# 16) that according to the WDLSQ inversion needs an adjustment of 0.94, and cruise 06MT19920509 (cruise \# 9) that requires a downward adjustment of 0.96. Also relevant are cruises 18HU19941012 (cruise \# 42), 06MT19960613 (cruise \# 14), 18HU19931105 (cruise \# 40), 33RO19980123 (cruise \# 85), 06MT19990610 (cruise \#20) and 74DI19970807 (cruise \# 171) that according to the WDLSQ inversion need adjustments of 0.98. Cruise 74DI19970807 is a special case that will be discussed in Subsect. 4.1.9.

The manual editing process used these results and evaluated for each cruise whether the suggested adjustment was warranted or not. In general, no adjustment was applied if the suggested adjustment was within the $1 \%$ threshold barriers, while the adjustment suggested by WDLSQ was adopted in the other cases. Special cases are discussed below.

The distribution of the offsets after the manually edited adjustments have been applied is shown in Fig. 6e. The adjustments substantially reduced the number of crossovers that are statistically different from 1 , i.e. from $57 \%$ to $35 \%$, but it did not reduce it down to zero. This is due to two factors: First, the $1 \%$ threshold was used even in cases where the recommended adjustment was significantly different from zero; second, some cruises were not adjusted despite them having substantial offsets.

To check the results we re-ran the three inversions (Fig. $6 \mathrm{f}-$ h) and re-computed the adjustments using the already adjusted cruise data. As shown by the red symbols in Fig. 7, the vast majority of the recommended adjustments are now indeed within the threshold barriers and only few cruises are outside. These outlying cruises have been carefully evaluated, and no adjustment was applied for reasons discussed in the following subsections.

\subsection{Discussion of special cases}

In this section we discuss the cruises that during our evaluation needed special consideration. We provide here only 


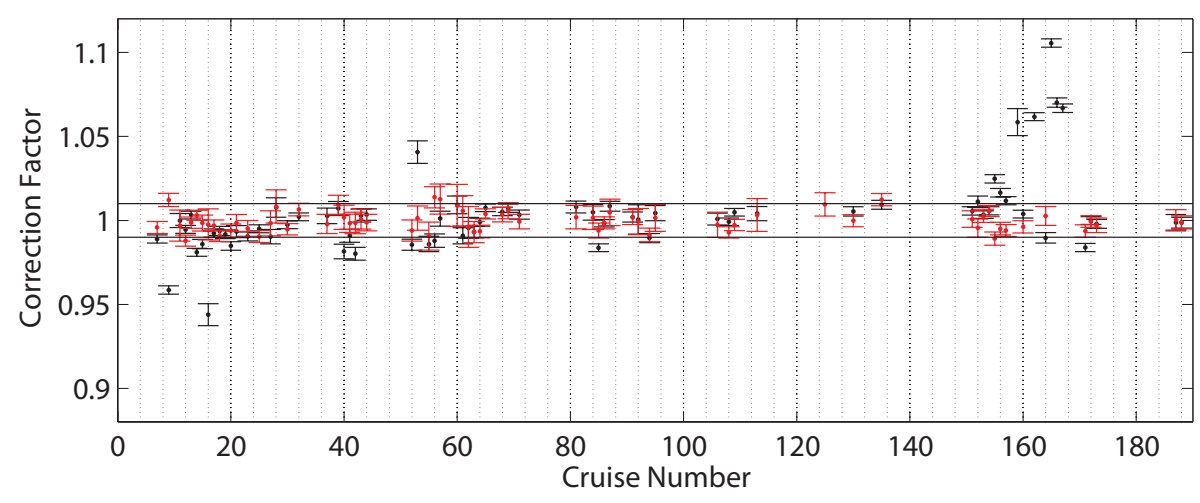

Figure 7. Plot of the individual cruise corrections and their uncertainties based on the WDLSQ method (see Table 1). In black are the corrections before any adjustment has been applied, i.e. the results from the first inversion of the offset results. In red are the corrections that the WDLSQ inversion suggests after the manually edited adjustments were applied to the oxygen data (see Table 1). The thin black lines represent the threshold of $1 \%$ of allowed adjustments. Cruises for which only red symbols are shown did not change their cruise adjustment from the initial to the second inversion. Cruises for which only black symbols are shown are those whose oxygen data have been flagged as questionable and deleted in the adjusted dataset.

the summary statements. More details, such as figures from each crossover as well as more detailed comments about each cruise can be found at http://cdiac.ornl.gov/oceans/ CARINA/Carina_inv.html. The cruises are identified with an expocode that contains the country information, ship information, and the date of when the ship left the port.

\subsection{1 cruise 74AB19900528 cruise \#159}

This cruise took place in the eastern part of the Mid-Atlantic Ridge from 28 May to 15 June 1990, covering a small area with 71 stations. Only 3 stations have oxygen data and only 1 station has samples from depths greater than $500 \mathrm{~m}$. Although the inversion suggested a substantial adjustment of 1.06 (see Table 1), this result is insufficient to warrant action as it is based on a single station. We agreed to label the cruise as NC (no suggestion of adjustment possible) in the on-line table and to flag this cruise for oxygen because of the uncertainty about the quality of the data.

\subsection{2 cruise 29CS19930510 cruise \#52}

This cruise took place from 10 May to 1 June 1993, covering 92 stations located off the western coast of Iberian Peninsula. The WDLSQ inversion suggested a downward adjustment of 0.982 (see Fig. 7). Because of the coastal location of the cruise with less than an half of the stations deeper than $1500 \mathrm{~m}$, and because the crossovers did not reveal clear offsets, especially those with the core cruises, we recommend no adjustment for this cruise.

\subsection{3 cruise 74DI19890511 cruise \# 165}

This cruise (from 11 May to 7 June 1989) has 990 stations along a section from $46^{\circ} \mathrm{N}$ to $60^{\circ} \mathrm{N}$ on $20^{\circ} \mathrm{W}$; along another section from $23^{\circ} \mathrm{W}$ and $59^{\circ} \mathrm{N}$ to $8^{\circ} \mathrm{W}$ and $56^{\circ} \mathrm{N}$, and a station group centered on $23^{\circ} \mathrm{W}$ and $59^{\circ} \mathrm{N}$. Almost all data are from the top $250 \mathrm{~m}$. Only 5 stations have oxygen data deeper than $1500 \mathrm{~m}$, and for those stations the inversion gave an adjustment of 1.11. This is outside the range in order for these data to be considered to be good enough to be included in the dataset. For that reason we agreed to flag the entire cruise for oxygen because of the poor quality of the data.

\subsection{4 cruise 74DI19890612 cruise \# 166}

This cruise (from 12 June to 9 July 1989) took place in the area $46^{\circ}-60^{\circ} \mathrm{N}$ and $10^{\circ}-22^{\circ} \mathrm{W}$ and has 87 stations, but only 3 stations have deep oxygen data. As was the case with the previous Discovery cruise (74DI19890511), we agreed to flag the oxygen data as questionable from the entire cruise because of the lack of sufficient deep data and too high offsets.

\subsection{5 cruise 74DI19890716 cruise \# 167}

This cruise (from 16 June to 10 August 1989) has 34 stations with 17 of them containing deep oxygen data that can be compared with other cruises in the same area. Also for this Discovery cruise the inversion suggested a substantial upward adjustment, i.e. 1.07 (Table 1). The vertical $\mathrm{O}_{2}$ profiles reveal a lot of scatter in the data. Taking into account the large suggested adjustment and in order to be consistent with the decisions regarding the previous Discovery cruises (see Subsects. 4.1.3 and 4.1.4), we decided to flag the oxygen data as questionable. 


\subsection{6 cruise 29GD19840218 cruise \# 55}

This cruise (18 February to 7 March 1984) is one of the Galicia cruises (Galicia 7) that took place off the northwestern part of the Iberian Peninsula. It has 33 stations but none of them have oxygen data from deeper than about $2000 \mathrm{~m}$. Although the inversion WDLSQ suggested a downward adjustment of about 0.98 (see Table 1 and Fig. 7), we agreed that no adjustment was warranted. The main arguments were (i) the lack of deep oxygen data, and (ii) the lack of clear offsets to other cruises.

\subsection{7 cruises 06MT19920316, 06MT19920509 and 06MT19920701 cruises \# 8, 9 and 10}

Originally those three cruises were considered as a single cruise 06MT19920322. But differing offsets (especially those for salinity) made it clear that this cruise needs to split into three single cruises. For oxygen, only the 06MT19920509 has stations with enough oxygen data to compute the offsets to the other cruise of the dataset, while cruises 06MT19920316 and 06MT19920701 do not have oxygen measurements. The cruise 06MT19920509, as shown by the solution from the inversion WDLSQ (Fig. 7), needs a conspicuous upward adjustment of 0.96 that we applied at the final product.

\subsection{8 cruise 74AB20050501 cruise \# 164}

This cruise is an Atlantic zonal section at $36^{\circ} \mathrm{N}$. With 144 full depth stations. The inversion suggests a downward adjustment of 0.99. However, the crossovers with core cruises reveals that the oxygen data from this cruise are higher only in the western part of the transect, while no offsets are evident in the eastern part. We checked the cruise report and we saw that the first 43 stations had a calibration problem. Based on this evidence we agreed to split the cruise into two parts: stations 1 to 43, for which we recommend an adjustment of 0.94 in agreement with the crossover offsets with the two core cruises 316N19970815 and 316N20031013; and a second part from stations 44 to 144 , which does not require an adjustment as evidenced by its high consistency with the core cruise 33RO20030604.

\subsection{9 cruise 74DI19970807 cruise \# 171}

This core cruise took place from 7 August to 17 September 1997 and has 143 stations along four different sections: a long section from $60^{\circ} \mathrm{N}$ and $43^{\circ} \mathrm{W}$ (south coast of Greenland) to $40^{\circ} \mathrm{N}$ and $9^{\circ} \mathrm{W}$ (western coast of Iberian Peninsula), a section from $63^{\circ} \mathrm{N}$ and $20^{\circ} \mathrm{W}$ (south of Iceland) to $57^{\circ} \mathrm{N}$ and $8^{\circ} \mathrm{W}$ crossing the Iceland Basin and the Rockall Plateau, a short section of 9 stations from $63^{\circ} \mathrm{N}$ and $41^{\circ} \mathrm{W}$ to $61.4^{\circ} \mathrm{N}$ and $35.7^{\circ} \mathrm{W}$ in the Irminger Sea, and a group of 8 stations in the northern part of the Irminger Sea at around $65^{\circ} \mathrm{N}$ from 27 to $30^{\circ} \mathrm{W}$. The WDLSQ inversion suggests an adjustment of 0.98 , but this is not confirmed by the crossovers with other core cruises. Moreover, considering that this cruise has 4 different sections, and that one of them is located just south of the Iceland where the ocean exhibits high temporal variability, we recommend no adjustment for this cruise.

This cruise as well as \#12 and \#13 (see subsection 4.1.10) was included in the GLODAP dataset despite the fact that we generally exclude cruises that were in GLODAP (Tanhua et al., 2009a). These cruises were added to CARINA because additional parameters, critical to the CARINA goals, became available after GLODAP was published (Tanhua et al., 2009c). In GLODAP (cruise \# 25 in GLODAP), a correction of $-6.79 \mu \mathrm{mol} \mathrm{kg} \mathrm{kg}^{-1}$ was applied to this particular cruise based on Gouretski and Jancke (2001) (note that the corrections are of additive kind). This corresponds to an about $2 \%$ downward adjustment, in line with what our inversion suggested. Since our analysis included a careful cruise-by-cruise inspection and evaluation of the suggested adjustments including a full documentation of the results (http://cdiac.ornl.gov/ftp/oceans/CARINA/CARINA Database/CARINA.ATL.V1.0/), while in GLODAP the oxygen corrections were taken straight from a previous work based on Gouretski and Jancke (2001), we recommend to use the data from the CARINA dataset for this cruise.

\subsubsection{0 cruises 06MT19941012 and 06MT19941115 cruises \# 12, and 13}

These cruises are also present in the GLODAP database, and were included in CARINA for the same reasons as cruise \# 171. GLODAP has applied slightly different adjustments, $3.01 \mu \mathrm{mol} \mathrm{kg}{ }^{-1}$ for cruise \# 12 and $-0.17 \mu \mathrm{mol} \mathrm{kg}{ }^{-1}$ for cruise \# 13. These adjustments are small and lower than our threshold $(1 \%)$ above which we made adjustments. Indeed, the offsets between these unadjusted CARINA cruises and their corresponding adjusted GLODAP representation are negligible.

\section{Summary and conclusions}

Based on the secondary quality control of the CARINAOxygen dataset, we recommend adjustments for 23 out of the 98 cruises. Most adjustments were between $\pm 1 \%$ and $\pm 2 \%$ with only five cruises needing an adjustment larger than $2 \%$. In addition, we regard the data from 4 cruises as of insufficient quality for climate-type studies, and therefore recommend these data to be flagged. However, this affects only 2002 data points out of the 103414 oxygen samples in the CARINA-Oxygen dataset. We also suggest an adjustment for a reference cruise (317519930704) that will not appear in the final product. This is consistent with the adjustment proposed by Johnson and Gruber (2007) but different from GLODAP where two different adjustments were inadvertently applied at the same time (Table 10 note d Sabine et al., 2005). 
The quality controlled oxygen data in the CARINAOxygen data will constitute a rich source of information to explore the impact of climate variability and change on the ocean's oxygen cycle and to extend the analysis conducted thus far in the Atlantic (e.g. Johnson et al., 2005; Johnson and Gruber, 2007). Oxygen is one of the best tracers to detect changes in biological and physical processes in the ocean's interior (Plattner et al., 2002; Deutsch et al., 2005; Körtzinger et al., 2006) because of its high signal-to-noise ratio. Its signal is particularly large because the physical and biological processes driving oxygen variability tend to enhance each other (Gruber et al., 2001). This is different from dissolved inorganic carbon, for which most processes tend to lead to opposing effects (Gruber and Sarmiento, 2002). As a result, one expects substantial decreases in the ocean's oxygen content in the future, since ocean warming and increased stratification will reduce the ocean's holding capacity for oxygen and the replenishment of the interior ocean with oxygen from the near surface (Matear et al., 2000; Plattner et al., 2002; Bopp et al., 2002; Keeling et al., 2010). This may be exacerbated by ocean acidification, which will lead to reduced production of mineral $\mathrm{CaCO}_{3}$ and hence less ballasting, causing the exported organic matter to remineralize at shallower depth. As a consequence, the thermocline regions with already low oxygen may substantially expand (Oschlies et al., 2008; Hoffmann and Schellnhuber, 2009; Keeling et al., 2010). Such expansions of the oxygen minimum zones have been observed (Stramma et al., 2008), although it is presently unclear whether this is already a consequence of climate change.

The sparsity of the hydrographic observations of $\mathrm{O}_{2}$ makes estimates of inventory changes difficult (Hamme and Keeling, 2008), so the data that have been collected must be utilized to the fullest and centralized. Much insight has been already gained by the analysis of historical $\mathrm{O}_{2}$ data measured during the latter decades of the 20th century revealing large-scale changes in subsurface $\mathrm{O}_{2}$ concentration in different basins of the global ocean (Johnson and Gruber, 2007; Emerson et al., 2001; Bindoff and McDougall, 2000). Thus we expect the CARINA dataset, with excellent temporal and spatial coverage as well as careful quality control, will serve as a critical resource for the research community. Furthermore, combining the CARINA oxygen data with the quality controlled carbon data from the CARINA-carbon dataset (Pierrot et al., 2009) along with other tracers (Steinfeldt et al., 2009; Tanhua et al., 2009a,c; Velo et al., 2009), provides us with a unique opportunity toward describing the recent changes in ocean biogeochemistry.
Acknowledgements. This work was supported by funds from ETH Zurich. We are grateful to T. Tanhua for his valuable contribution and for leading the ATL group. We thank the numerous scientists and analysts responsible for the collection, and the analysis of the large amount of data that form the CARINA dataset. Without their contribution this project would not have been possible.

Edited by: M. Hoppema

\section{References}

Bindoff, N. L. and McDougall, T. J.: Decadal changes along an Indian ocean section at 32 degrees $\mathrm{S}$ and their interpretation, J. Phys. Oceanogr., 30, 1207-1222, 2000.

Bopp, L., Le Quéré, C., Heimann, M., Manning, A. C., and Monfray, P.: Climate-induced oceanic oxygen fluxes: Implications for the contemporary carbon budget, Global Biogeochem. Cy., 16, 1022, doi:10.1029/2001GB001445, 2002.

Deutsch, C., Emerson, S., and Thompson, L.: Fingerprints of climate change in North Pacific oxygen, Geophys. Res. Lett., 32, L16604, doi:10.1029/2005GL023190, 2005.

Emerson, S., Mecking, S., and Abell, J.: The biological pump in the subtropical North Pacific Ocean: Nutrient sources, Redfield ratios, and recent changes, Global Biogeochem. Cy., 15, 535554, 2001.

Gouretski, V. V. and Jancke, K.: Systematic errors as the cause for an apparent deep water property variability: global analysis of the WOCE and historical hydrographic data, Prog. Oceanogr., 48, 337-402, 2001.

Gruber, N. and Sarmiento, J. L.: Larg-scale Biogeochemical/Physical Interactions in Elemental Cycles, in: THE SEA: Biological-Physical Interactions in the Oceans, edited by: Robinson, A., McCarthy, J., and Rothschild, B., Vol. 12, 337-399, John Wiley and Sons, New York, 2002.

Gruber, N., Gloor, M., Fan, S. M., and Sarmiento, J. L.: Air-sea flux of oxygen estimated from bulk data: Implications for the marine and atmospheric oxygen cycles, Global Biogeochem. Cy., 15, 783-803, 2001.

Hamme, R. C. and Keeling, R. F.: Ocean ventilation as a driver of interannual variability in atmospheric potential oxygen, Tellus $\mathrm{B}$, 60, 706-717, doi:10.1111/j.1600-0889.2008.00376.x, 2008.

Hoffmann, M. and Schellnhuber, H.-J.: Oceanic acidification affects marine carbon pump and triggers extended marine oxygen hole, PNAS, 106, 3017-3022, 2009.

Johnson, G. C. and Gruber, N.: Decadal water mass variations along 20 degrees $\mathrm{W}$ in the Northeastern Atlantic Ocean, Progr. Oceanogr., 73, 277-295, doi:10.1016/j.pocean.2006.03. 022, 2007.

Johnson, G. C., Robbins, P. E., and Hufford, G. E.: Systematic adjustments of hydrographic sections for internal consistency, J. Atmos. Ocean. Tech., 18, 1234-1244, 2001.

Johnson, G. C., Bullister, J. L., and Gruber, N.: Labrador Sea Water property variations in the northeastern Atlantic Ocean, Geophys. Res. Lett., 32, L07602, doi:10.1029/2005GL022404, 2005.

Keeling, R. F., Körtzinger, A., and Gruber, N.: Ocean deoxygengation in a warming world, Annu. Rev. Mar. Sci., 2, doi: 10.1146/annurev.marine.010908.163855, 2010. 
Key, R. M., Kozyr, A., Sabine, C. L., Lee, K., Wanninkhof, R., Bullister, J. L., Feely, R. A., Millero, F. J., Mordy, C., and Peng, T. H.: A global ocean carbon climatology: Results from Global Data Analysis Project (GLODAP), Global Biogeochem. Cy., 18, GB4031, doi:10.1029/2004GB002247, 2004.

Key, R. M., Tanhua, T., Olsen, A., Hoppema, M., Jutterström, S., Schirnick, C., van Heuven, S., Kozyr, A., Lin, X., Velo, A., Wallace, D. W. R., and Mintrop, L.: The CARINA data synthesis project: introduction and overview, Earth Syst. Sci. Data Discuss., 2, 579-624, 2009,

http://www.earth-syst-sci-data-discuss.net/2/579/2009/.

Körtzinger, A., Riser, S. C., and Gruber, N.: Oceanic oxygen: the oceanographer's canary bird of climate change, ARGO Newsletter, 7, 2-3, 2006.

Lamb, M. F., Sabine, C. L., Feely, R. A., Wanninkhof, R., Key, R. M., Johnson, G. C., Millero, F. J., Lee, K., Peng, T. H., Kozyr, A., Bullister, J. L., Greeley, D., Byrne, R. H., Chipman, D. W., Dickson, A. G., Goyet, C., Guenther, P. R., Ishii, M., Johnson, K. M., Keeling, C. D., Ono, T., Shitashima, K., Tilbrook, B., Takahashi, T., Wallace, D. W. R., Watanabe, Y. W., Winn, C., and Wong, C. S.: Consistency and synthesis of Pacific Ocean $\mathrm{CO}_{2}$ survey data, Deep-Sea Res. Pt. II, 49, 21-58, 2002.

Matear, R. J., Hirst, A. C., and McNeil, B. I.: Changes in dissolved oxygen in the Southern Ocean with climate change, Geochem. Geophys. Geosyst., 1, 2000GC000086, 2000.

Oschlies, A., Schulz, K. G., Riebesell, U., and Schmittner, A.: Simulated 21st century's increase in oceanic suboxia by $\mathrm{CO} 2-$ enhanced biotic carbon export, Global Biogeochem. Cy., 22, GB4008, doi:10.1029/2007GB003147, 2008.

Pierrot, D., Brown, P., van Heuven, S., Tanhua, T., Schuster, U., Wanninkhof, R., and Key, R. M.: CARINA $\mathrm{TCO}_{2}$ data in the Atlantic Ocean, Earth Syst. Sci. Data Discuss., in press, 2009.

Plattner, G. K., Joos, F., and Stocker, T. F.: Revision of the global carbon budget due to changing air-sea oxygen fluxes, Global Biogeochem. Cy., 16, 1096, doi:10.1029/2001GB001746, 2002.
Sabine,C. L., Key, R. M., Kozyr, A., Feely, R. A., Wanninkhof,R., Millero, F. J., Peng,T.-H., Bullister,J. L., and Lee, K.: Global Ocean Data Analysis Project (GLODAP): Results and data, Rep. ORNL/CDIAC-145/NDP-083,1096, Carbon Dioxide Inf. Anal. Cent., Oak Ridge Natl. Lab., U.S. Dep. of Energy, Oak Ridge, Tenn., 2005.

Sarmiento, J. L. and Gruber, N.: Oncean Biogeochemical Dynamics, Princeton University Press, Princeton, New Jersey, 08540, 2006.

Steinfeldt, R., Tanhua, T., Bullister, J. L., Key, R. M., Rhein, M., and Köhler, J.: Atlantic CFC data in CARINA, Earth Syst. Sci. Data Discuss., 2, 27-61, 2009, http://www.earth-syst-sci-data-discuss.net/2/27/2009/.

Stramma, L., Johnson, G. C., Sprintall, J., and Mohrholz, V.: Expanding oxygen-minimum zones in the tropical oceans, Science, 320, 655-658, doi:10.1126/science.1153847, 2008.

Tanhua, T., Steinfeldt, R., Key, R. M., Brown, P., Gruber, N., Wanninkhof, R., Perez, F., Körtzinger, A., Velo, A., Schuster, U., van Heuven, S., Bullister, J. L., Stendardo, I., Hoppema, M., Olsen, A., Kozyr, A., Pierrot, D., Schirnick, C., and Wallace, D. W. R.: Atlantic Ocean CARINA data: overview and salinity adjustments, Earth Syst. Sci. Data Discuss., 2, 241-280, 2009a, http://www.earth-syst-sci-data-discuss.net/2/241/2009/.

Tanhua, T., van Heuven, S., Key, R. M., Velo, A., Olsen, A., and Schirnick, C.: Quality control procedures and methods of the CARINA database, Earth Syst. Sci. Data Discuss., 2, 205-240, 2009b, http://www.earth-syst-sci-data-discuss.net/2/205/2009/.

Tanhua, T., Brown, P. J., and Key, R. M.: CARINA: nutrient data in the Atlantic Ocean, Earth Syst. Sci. Data, 1, 7-24, 2009c, http://www.earth-syst-sci-data.net/1/7/2009/.

Velo, A., Perez, F. F., Brown, P., Tanhua, T., Schuster, U., and Key, R. M.: CARINA alkalinity data in the Atlantic Ocean, Earth Syst. Sci. Data, 1, 45-61, 2009, http://www.earth-syst-sci-data.net/1/45/2009/. 